\title{
ZMIANY BATYMETRII JEZIORA MIERZYŃSKIEGO
}

\author{
ADAM CHOIŃSKI, MARIUSZ PTAK \\ Uniwersytet im. Adama Mickiewicza w Poznaniu, \\ Wydział Nauk Geograficznych i Geologicznych, Zakład Hydrologii i Gospodarki Wodnej \\ ul. B. Krygowskiego 10, 61-680 Poznań
}

\begin{abstract}
The paper presents an analysis of changes in the bathymetry of Mierzyńskie lake, located in western Poland. It was found that over the last five decades this lake was characterized by exceptional stability in terms of changes in the surface area and volume of water, which decreased by 3.4 ha and $315,000 \mathrm{~m}^{3}$ respectively. The observed situation is quite different in comparison to the literature analysing the issue of lake evolution in Poland (indicating a faster rate of their disappearance). This specificity is due to the nature of the use of the catchment of this lake, which is characterised by an exceptionally high percentage of forest areas (considered to be the most natural) and negligible anthropopressure.
\end{abstract}

Keywords: bathymetry, lake evolution, drainage basin, Puszcza Notecka

\section{WSTĘP}

Jeziora polodowcowe od momentu swojego powstania podlegają ciągłej ewolucji, której ostatecznym rezultatem jest ich zanik. Tempo tych procesów jest różne i zależy zasadniczo od cech morfometrycznych jeziora, wielkości i charakteru użytkowania zlewni, warunków klimatycznych itd. Proces zaniku jezior może nastąpić wskutek wypełniania misy jeziornej osadami oraz oscylacji poziomu wody. W tym drugim przypadku szczególną rolę może odgrywać działalność człowieka, który m.in. w wyniku prac melioracyjnych może mieć wyraźny wpływ na wahania stanów wody. W skrajnych przypadkach dochodzi do całkowitego spłynięcia wody z jeziora (Choiński i in. 2012).

$\mathrm{Z}$ dotychczasowych danych uzyskanych na podstawie analizy zmian powierzchni wynika, że średni perspektywiczny wiek jezior w Polsce to około 2000 lat (Choiński 2007). Jest to niewiele w geologicznej skali czasu. Ponadto należy pamiętać, że misy jeziorne, będąc obiektami trójwymiarowymi, podlegają także procesowi zaniku związanemu $\mathrm{z}$ ich wypłycaniem. $\mathrm{Z}$ uwagi na wiele funkcji pełnionych przez jeziora $\mathrm{w}$ środowisku, zarówno w odniesieniu do jego elementów naturalnych (obieg wody, mikroklimat, bioróżnorodność itd.), jak i sztucznych - związanych z życiem człowieka (nawodnienia rolnicze, przemysł, turystyka itd.), oczywiste jest, aby jeziora funkcjonowały w środowisku jak najdłużej - spełniając w pełni powyższe (i nie tylko) role. Istotnym zagadnieniem jest kwestia deficytów wody obserwowana w różnych rejonach świata, 
a jeziora stanowią znaczące rezerwuary łatwo dostępnej (w przeciwieństwie np. do wód podziemnych) wody. Polska należy do krajów o jednych z najniższych zasobach wody w Europie (Kowalczak i in. 1997), które są porównywalne do obszarów strefy półsuchej. Chociażby z tego względu istotne jest posiadanie szczegółowych informacji na temat aktualnych zasobów wodnych zdeponowanych $\mathrm{w}$ jeziorach i zmian, jakim one podlegają.

Obiekt badań stanowi Jezioro Mierzyńskie (ryc. 1), położone w zachodniej Polsce w Puszczy Noteckiej. Celem pracy jest określenie współczesnej batymetrii tego jeziora i zasobów wodnych w nim zmagazynowanych oraz ich zmian. Jezioro Mierzyńskie do tej pory stanowiło rzadki obiekt badań. Wśród prac dotyczących analizowanego obiektu można wymienić m.in. opracowania Kubiaka i Ławniczaka (2014), Ławniczaka i Kubiaka (2016).

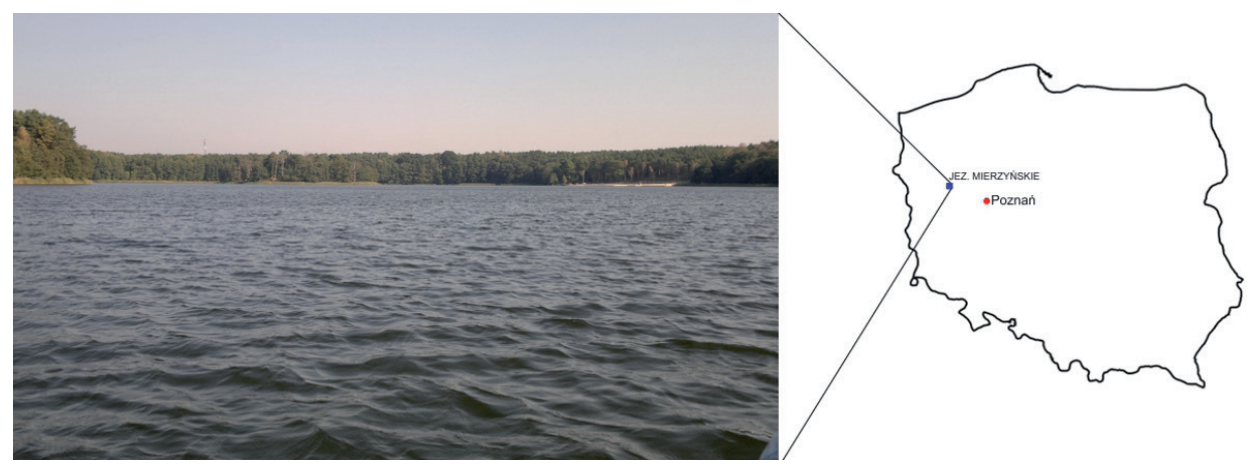

Ryc. 1. Lokalizacja obiektu badań

Fig. 1. Location of study object

\section{MATERIAŁY I METODY}

W pracy przyjęto metodykę zgodną z założeniami sformułowanymi przez Choińskiego i Ptaka (2014). W badaniach terenowych (wrzesień 2017) wykorzystano echosondę firmy Garmin Fishfinder $100(200 \mathrm{kHz})$ oraz odbiornik GPS Gar$\mathrm{min}$. Sondowania przeprowadzono według schematu przedstawionego na rycinie 2, tj. poruszając się „zygzakiem” w poprzek jeziora, odczytując jego głębokość oraz pozycję punktu, dla którego dokonywany był odczyt (w trakcie pomiarów poziom jeziora mieścił się w strefie stanów średnich). W ten sposób wykonano kilkaset (ok. 400) pomiarów głębokości. Dane te posłużyły do wykreślenia izobat oraz wyznaczenia parametrów morfometrycznych. Jednocześnie w kilkunastu punktach wykonano pomiary głębokości przy użyciu sondy ciężarkowej. Procedura taka pozwoliła na zweryfikowanie współczesnej metody pomiarów z metodą wykorzystywaną przez IRŚ, a w konsekwencji porównanie obu pomiarów. 


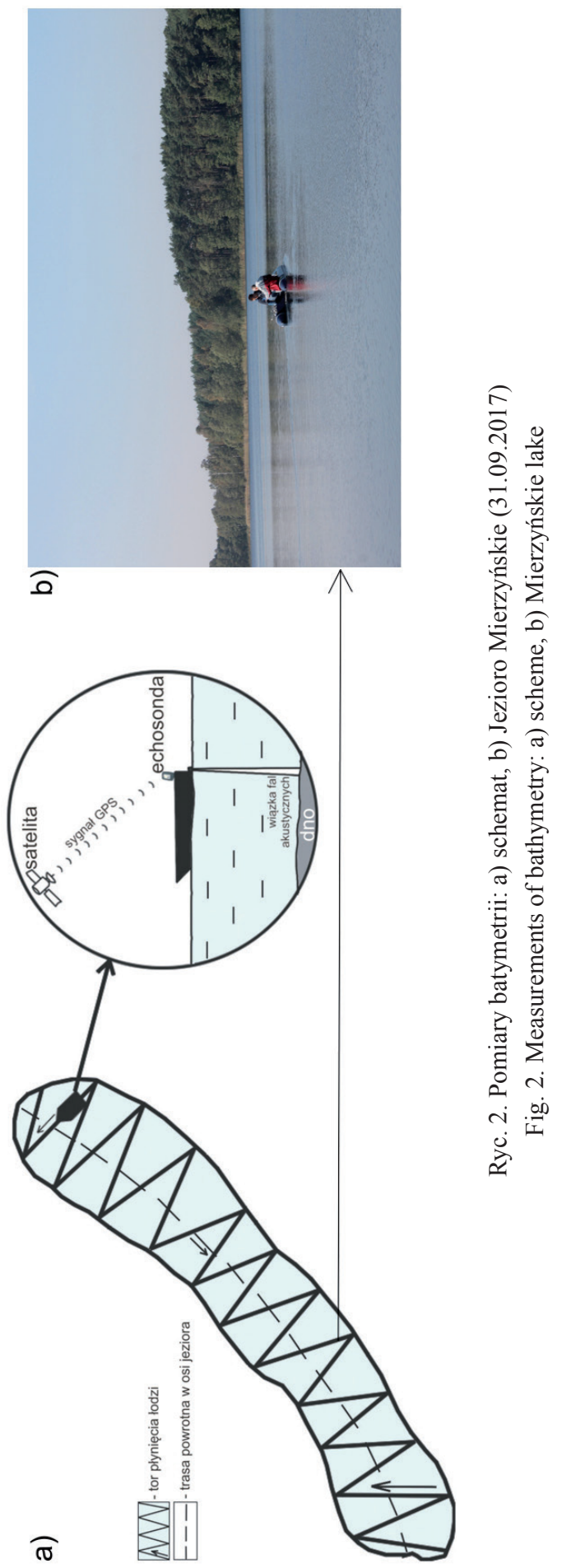




\section{WYNIKI I DYSKUSJA}

Współczesny oraz wcześniejszy plan batymetryczny Jeziora Mierzyńskiego przedstawiono na rycinie 3 .

Jezioro Mierzyńskie w ostatnich pięciu dekadach cechowało się względną stabilnością podstawowych parametrów morfometrycznych. Powierzchnia jeziora w tym okresie zmniejszyła się z 47,8 ha do 44,4 ha. Podobna sytuacje miała miejsce w przypadku batymetrii. Analizując rozkład głębokości, można stwierdzić, że w obu sytuacjach ich przebieg jest zbliżony. Generalnie zmiany, które nastąpiły na przestrzeni ponad pół wieku, widoczne są w przesunięciu izobat w kierunku środka jeziora. Należy jednak podkreślić, że zmiany te nie są znaczące. W wyniku aktualnych pomiarów ustalono, że zasoby wodne zmagazynowane w Jeziorze Mierzyńskim wynoszą 2232,4 tys. $\mathrm{m}^{3}$ i w okresie pięćdziesięciu lat zmniejszyły się o 315,8 tys. $\mathrm{m}^{3}$, a średnia głębokość o 0,3 $\mathrm{m}$ i wynosi aktualnie 5,0 m. Można stwierdzić, że sytuacja odnotowana dla analizowanego jeziora jest podobna jak w wielu innych przypadkach, gdzie odnotowuje się zarówno zmniejszeni powierzchni, jak i kurczenie zasobów wodnych. Dorożyński, Skowron (2002), Skowron (2004), Choiński i Ptak (2009), Kunz i in. (2011), Ptak (2013a, b), Choiński i in. (2014), Ławniczak $\mathrm{i}$ in. (2011), Choiński i in. (2016) przeanalizowali łącznie kilkadziesiąt jezior na obszarze północnej Polski, wykazując generalnie dynamiczny proces ich ewolucji, zmierzający do zaniku zbiornika. Można zatem stwierdzić, że analizowane jezioro jest wyjątkowo odporne na procesy powodujące jego zanik - zarówno w ujęciu horyzontalnym, jak i wertykalnym. O tempie ewolucji jezior decyduje kilka kluczowych czynników, do których zalicza się parametry morfometryczne danego jeziora oraz cechy zlewni (geologia, użytkowanie terenu, zrzuty ścieków itd.). Najbardziej odporne na zanik są jeziora głębokie, ponieważ dla ich zlewni charakterystyczna jest dominacja obszarów leśnych $\mathrm{i}$ brak antropopresji. W przypadku omawianego w pracy jeziora istotny jest ten drugi aspekt. Jezioro zlokalizowane jest na skraju Puszczy Noteckiej, jednego z największych w Polsce kompleksów leśnych. Zlewnia jeziora (ryc. 4) cechuje się wyjątkowo korzystnym układem. W strukturze jej pokrycia zdecydowanie dominują lasy (68\%).

Zlewnia alimentująca Jezioro Mierzyńskie odznacza się wyjątkowo niewielkim zaludnieniem (miejscowość Kaplin (110 mieszkańców) oraz sezonowe ośrodki wypoczynkowe). Tak więc brak zagrożeń w postaci dopływu biogenów z obszarów rolniczych przyspieszających eutrofizację oraz brak zrzutów ścieków stanowią o tym, że analizowane jezioro cechuje się powolną ewolucją. Kolejnym korzystnym elementem jest położenie innych jezior (Głęboczek, Szenińskie) powyżej analizowanego zbiornika. Akweny te stanowią odstojnik dla produktów erozji wymywanych w górnych partiach zlewni, ograniczając ich dopływ do Jeziora Mierzyńskiego. O roli kaskady zbiorników 


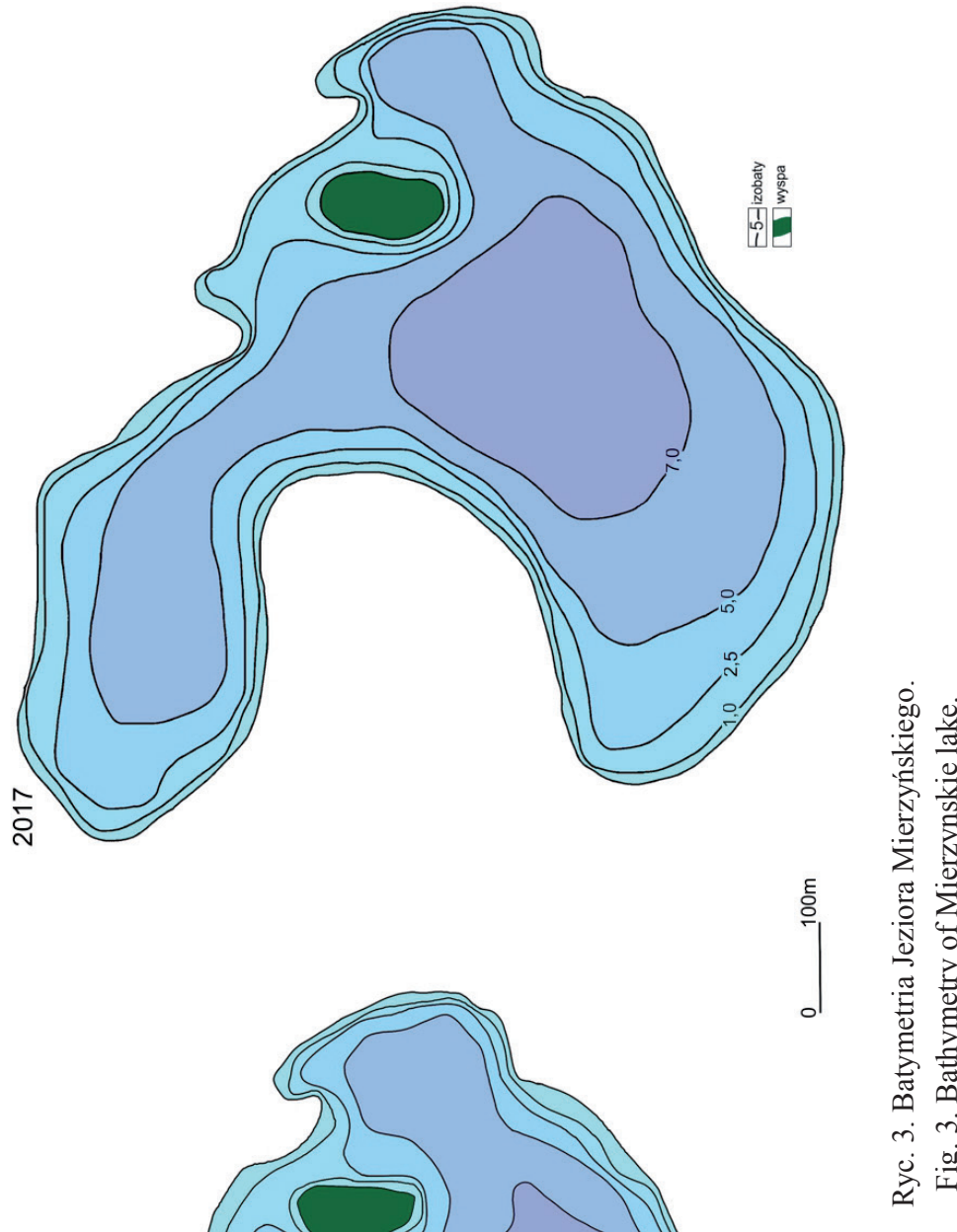




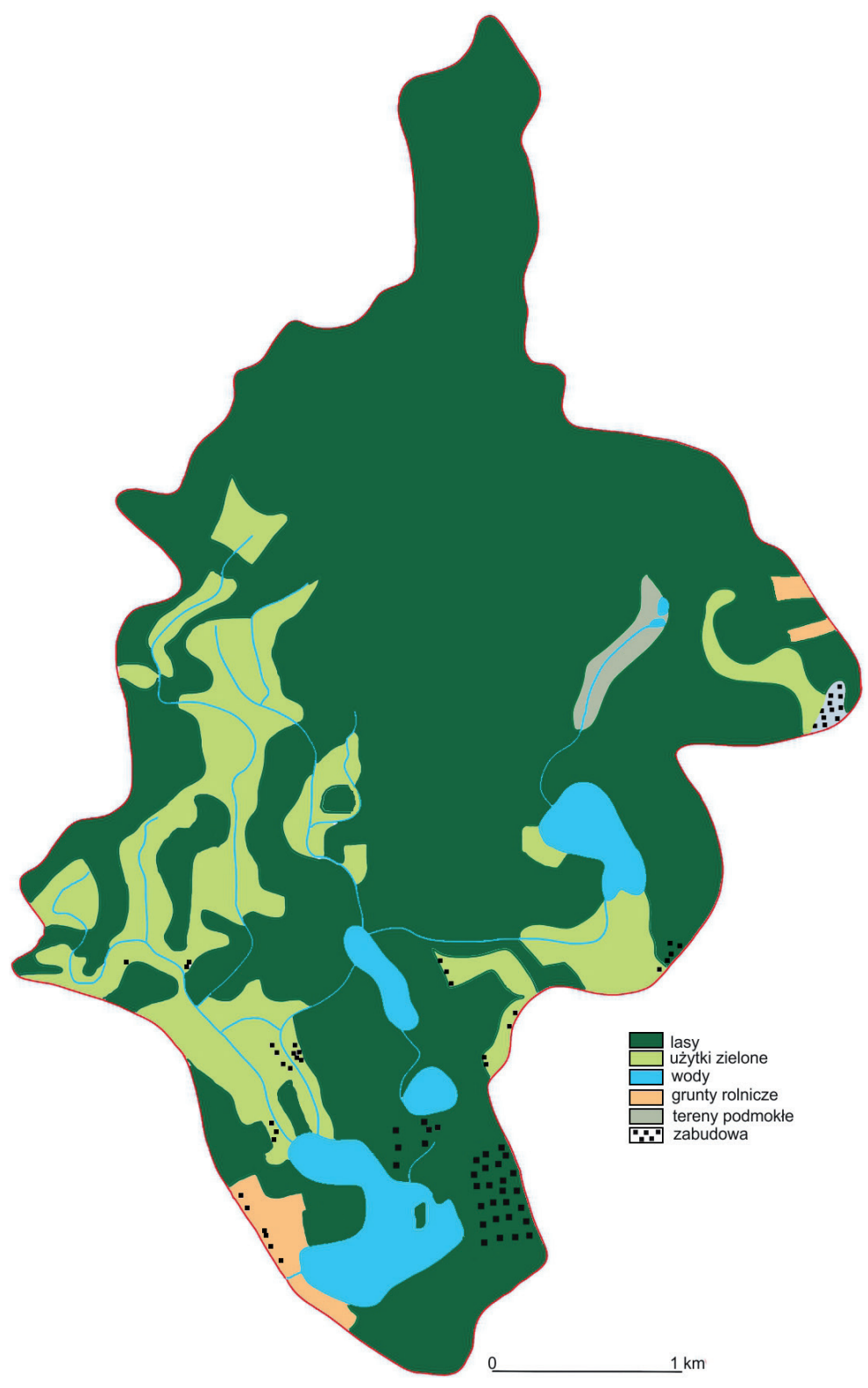

Ryc. 4. Struktura użytkowania zlewni Jeziora Mierzyńskiego.

Fig. 4. Structure of use of the Mierzyńskie lake catchment area.

wodnych w depozycji materii może świadczyć przykład nieistniejącego jeziora Makąty, położonego w omawianej zlewni powyżej Jeziora Szenińskiego. Jezioro o powierzchni około 18 ha zanikło w stosunkowo niedługim okresie (ryc. 5). 


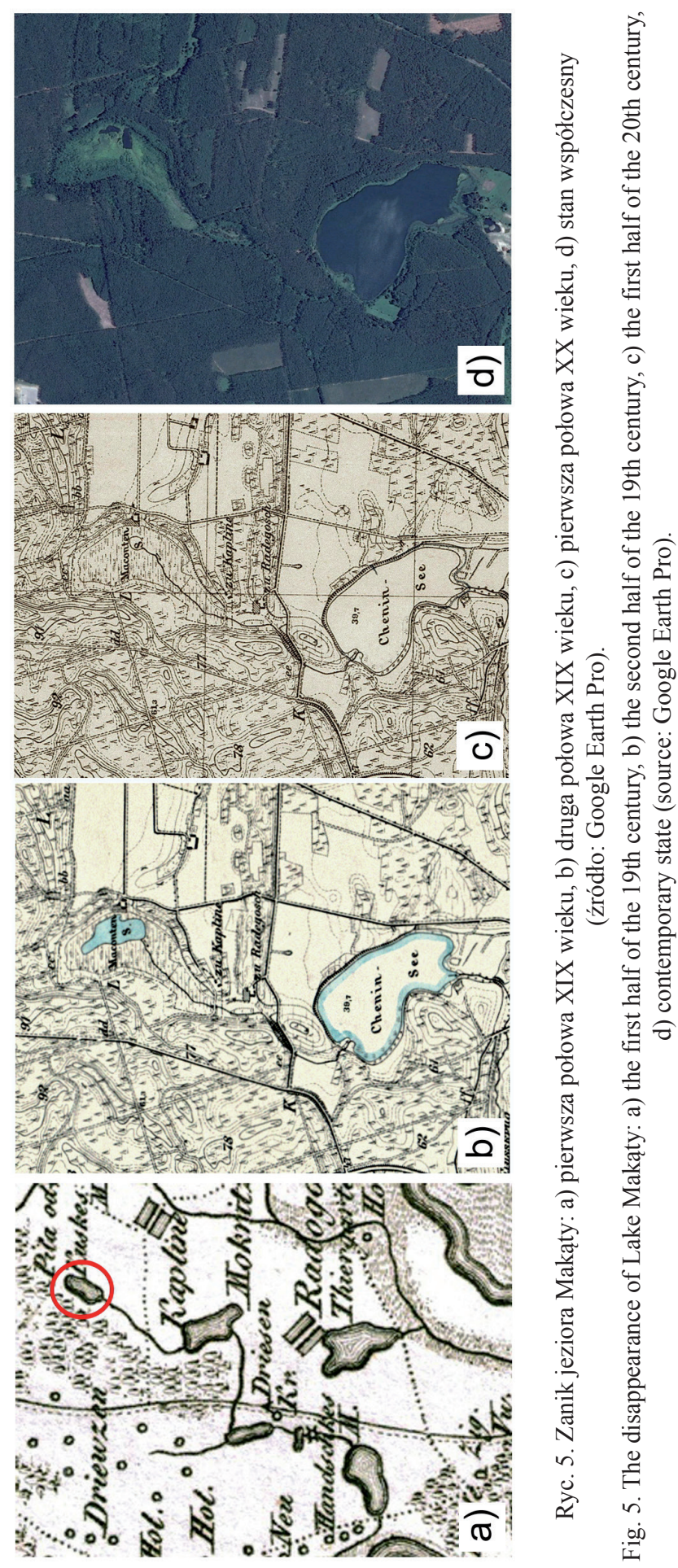


Jedną z przyczyn takiego stanu mogła być znaczna depozycja materii wymywanej powyżej tego jeziora i deponowanej w jego niecce, czemu sprzyjało znaczne nachylenie stoków przyjeziornych. To z kolei przyspieszyło wypłycanie zbiornika i stworzenie dogodnych warunków dla ekspansji roślinnej.

Dalsze zmiany morfometrii Jeziora Mierzyńskiego mogą być najbardziej widoczne w rejonie istniejącej tam wyspy (ryc. 6), a sukcesja roślinna z uwagi na stosunkowo niedużą głębokość pomiędzy nią i lądem będzie postępowała nie tylko od brzegu jeziora, ale też w kierunku przeciwnym.
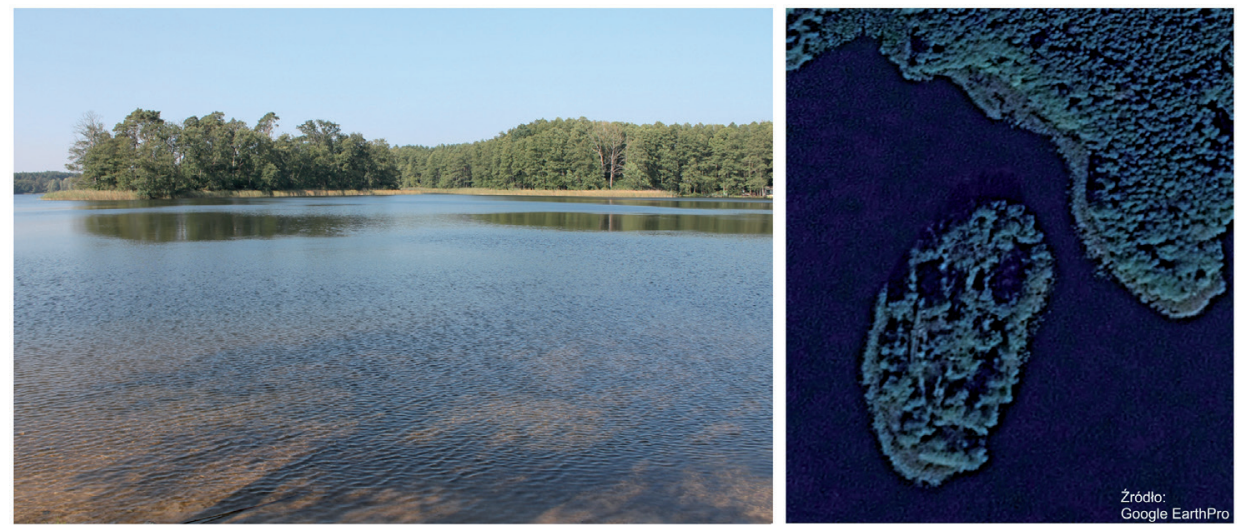

Ryc. 6. Wyspa na Jeziorze Mierzyńskim

Fig. 6. Island on Mierzyńskie lake

\section{PODSUMOWANIE}

$\mathrm{Z}$ przedstawionej w pracy analizy powierzchni i batymetrii Jeziora Mierzyńskiego wynika, że podczas około pięćdziesięciu lat nastąpiła niewielka ich transformacja. Jezioro na tle innych przykładowych zbiorników przytaczanych w literaturze cechowało się dużą stabilnością swoich elementarnych cech. Sytuację taką $\mathrm{z}$ uwagi na pełnione przez jeziora funkcje $\mathrm{w}$ środowisku należy uznać za wyjątkowo korzystną. Kluczowe dla zaistniałego stanu było zagospodarowanie zlewni (dominacja użytków leśnych oraz brak intensywnej antropopresji). Analizowany przypadek w jednoznaczny sposób potwierdza rolę struktury użytkowania zlewni i jej naturalnego (quasi-naturalnego) charakteru w ochronie ekosystemów wód powierzchniowych. Z pewnością odnotowane fakty są istotne dla planistów, samorządów czy agend związanych z gospodarką wodną i ochroną środowiska. Wynika z nich, w jakim kierunku należy kształtować relacje zlewnia-jezioro, aby utrzymać jezioro najdłużej w środowisku przyrodniczym jako element wpływający na jego różnorodność i atrakcyjność. 


\section{LITERATURA}

Choiński A., 2007: Limnologia fizyczna Polski, Wyd. UAM, Poznań.

Choiński A., Ławniczak A., Ptak M., 2016: Changes in water resources of Polish lakes as influenced by natural and anthropogenic factors, Polish Journ. of Environmental Stud., 25, 5, $1883-1890$.

Choiński A., Ptak M., 2009: Lake Infill as the Main Factor Leading to Lake's Disappearance, Polish Journ. of Environmental Stud., 18, 3.

Choiński A., Ptak M., 2014: Najnowsze sondowania jezior Pojezierza Wielkopolsko- Kujawskiego, Bad. Fizjogr., 65, A, 55-63.

Choiński A., Ptak M., Strzelczak A., 2012: Examples of Lake disappearance as an effect of reclamation Works in Poland, Limnol. Rev., 4, 161-167.

Choiński A., Ptak M., Strzelczak A., 2014: Present-day evolution of coastal lakes based on the example of Jamno and Bukowo (the Southern Baltic coast), Oceanological and Hydrobiol. Stud., 43, 2, 178-184.

Dorożyński R., Skowron R., 2002: Changes of the basin of Lake Gopto caused by melioration work in the 18th and 19th centuries, Limnol. Rev., 2, 93-102.

Kowalczak P., Farat R., Kepińska-Kasprzak M., Kuźnicka M., Mager P., 1997: Hierarchia potrzeb obszarowych matej retencji. Materiaty badawcze, IMGW, Warszawa.

Kubiak J., Ławniczak R., 2014: Położenie, powierzchnia i ksztalt wybranych jezior Pojezierza Międzychodzko-Sierakowskiego na mapach topograficznych, Bad. Fizjograf., A 65, 193-203.

Kunz M., Skowron R., Skowroński S., 2011: Morphometry changes of Lake Ostrowskie (the Gniezno Lakeland) on the basis of cartographic, remote sensing and geodetic surveying, Limnol. Rev., 10, 2, 77-85.

Ławniczak A.E., Choiński A., Kurzyca I., 2011: Dynamics of lake morphometry and bathymetry in various hydrological conditions, Polish Journ. of Environmental Stud., 20, 4, 931-940.

Ławniczak R., Kubiak J., 2016: Geometric accuracy of topographical objects at Polish topographic maps, Geod. and Cartography, 65, 1, 55-66.

Ptak M., 2013a: Lake evolution in the Żnin region in the years 1912-1960 (central Poland), Quaes. Geograph., 32, 1.

Ptak M., 2013b: Zmiany powierzchni i batymetrii wybranych jezior Pojezierza Pomorskiego, Pr. Geogr., 133, 61-76.

Skowron R., 2004: Description of lake basin in the light of selected morphometric indicators, Limnol. Rev., 4, 233-240. 